$\S=-1$

\title{
The Use of Heat From the Incineration of Municipal Solid Waste for Processing of Phosphogypsum
}

\author{
Olga Krot $^{1 *}$, Varvara Vinnichenko ${ }^{1}$ \\ ${ }^{1}$ Kharkiv National University of Civil Engineering and Architecture \\ *Corresponding author E-mail: uch.opk@gmail.com
}

\begin{abstract}
Municipal landfills and open dumps with industrial waste are global issues which impact on the environment and on the health of populations. The production of phosphoric acid from natural phosphate rock gives rise to an industrial by-product called phosphogypsum, containing mainly dihydrated gypsum. Five tons of phosphogypsum are generated per ton of phosphoric acid production. The technology of roasting of phosphogypsum in a dehydrator, which is a mine, has been described in the article. Such reprocessing of the waste makes it possible to obtain a ready-made high-quality building material. The development of a complex that processes wet and highly adhesive phosphogypsum using the heat of combustion of alternative fuel (municipal waste) is consistent with the synergetic concept of environmentally efficient utilization. Experimental studies identify the most rational parameters of the dehydrator, namely, its operating temperature, have been conducted. The temperature of a heat carrier (air) varied from $175^{\circ} \mathrm{C}$ to $350{ }^{\circ} \mathrm{C}$ in the experiment.
\end{abstract}

Keywords: energy Intensity; incineration; municipal waste; roasting of phosphogypsum; rotary kiln.

\section{Introduction}

A large number of industrial and domestic wastes accumulated in Ukraine. Waste is stored on landfills or dumps. Production and waste disposal are a source of uncontrolled environmental pollution, which have a negative impact for a long time. Phosphogypsum is one of the most multi-tonnage solid wastes of production of mineral fertilizers. There are four types of phosphogypsum in Ukraine: phosphogypsum from apatite concentrate have a shelf life 10-30 years in the tailings; phosphogypsum from phosphorites on the dump with a shelf life of less than ten years; phosphogypsum from phosphorites that was recently formed and dump phosphogypsum from uranium-containing phosphorites obtained. Phosphogypsum contains in its composition more than $90 \%$ of the crystals of $\mathrm{CaSO}_{4} \cdot 2 \mathrm{H}_{2} \mathrm{O}$, but also contains impurities such as phosphates, fluorides and sulfates, radionuclides that occur naturally, heavy metals and other microelements. All this leads to a negative impact on the environment when storing phosphogypsum in the dump [1]. The bioavailability of radionuclides was evaluated [2] from the Brazilian phosphoric acid producers. The results show that although all these elements are enriched in the phosphogypsum samples they are not associated with $\mathrm{CaSO}_{4}$ itself and therefore do not represent a threat to the surrounding aquatic environment. The radioactivity of phosphogypsum should be measured and accounted in each specific case. The production of phosphoric acid from apatite concentrate produces $4 \div 6$ tons of waste per 1 ton of useful product, which contain phosphogypsum. The issue of processing gypsum-containing waste is especially urgent. There are various uses of phosphogypsum: the use of phosphogypsum in the production of building materials [3,4]; application in the construction of auto-mobile roads [5,6]; utilization as fertilizer in agriculture [7].

The conversion of phosphogypsum (calcium sulphate dihydrate $\left.\mathrm{CaSO}_{4} \cdot 2 \mathrm{H}_{2} \mathrm{O}\right)$ into (construction) gypsum $\left(\mathrm{CaSO}_{4} \cdot 0,5 \mathrm{H}_{2} \mathrm{O}\right.$ - calci- um sulphate hemihydrate) by roasting in a finely dispersed state is the most cost-effective use of this waste. In author's view, the main problem of the conversion phosphogypsum into hemihydrate gypsu is not so much the environmental hazard of impurities entering from the phosphogypsum from a dump, as in its finely dispersed nature, the presence of physical moisture in it, as well as in the difference in crystal structure in comparison with dihydrate gypsum of fossil. Moisture of phosphogypsum in dumps high and variable, varies from 20 to $40 \%$ depending on the season and the amount of precipitation. Moisture of natural gypsum stone usually does not exceed 5-8\%. This explains the lower energy intensity and greater stability of the process of production of construction gypsum from fossil natural dihydrate. The problem of lowering the energy intensity of production is of paramount importance not only in terms of energy independence, but also from the point of view of ensuring competitiveness of products both on the external and internal markets. The production of gypsum requires the improvement of the technological process of heat treatment in order to reduce the cost of energy resources taking into account environmental problems. However, the energy intensity of gypsum binders at enterprises exceeds similar indicators of foreign countries, so it is necessary to look for ways to reduce energy costs for thermal processing of gypsum binders. Solving energy saving problems is becoming increasingly important in the face of everincreasing prices for fuel resources. The theoretical energy requirement of chemical reactions in the process of obtaining gypsum binders is, on average, four times less than the production of cement clinker, but the actual costs of heat in industrial conditions are at the same level, and sometimes exceed the costs of obtaining cement clinker. The development of a complex that can process wet and highly adhesive phosphogypsum, which will use the heat of combustion of alternative fuel - household waste consistent with the synergetic concept of environmentally efficient waste management. 
Nowadays in Ukraine there is no modern and environmentally safe system of handling and disposal of municipal solid waste (MSW). Landfills or illegal landfills occupy a large number of territories. An efficient and quick way to dispose of MSW can be to incineration of them. The main advantages of incineration are a significant reduction in the volume of waste and the possibility of obtaining thermal and / or electrical energy. There are many different furnace designs and combustion techniques in use for municipal solid waste (MSW) incineration, namely: in rotary kilns, thermal processing of waste using pyrolysis, combustion on grate furnace in layer furnaces, combustion in cement kilns, incineration in fluidized beds [8]. In the process of incineration waste in rotary kilns pass away several temperature zones: drying; preparation of waste for incineration; ignition; burning; afterburning. Combustion of solid waste begins when the layer temperature reaches about $600{ }^{\circ} \mathrm{C}$. The temperature in the furnace depends on a type of waste. The afterburning chamber, is used for complete neutralization of toxic components, for this the temperature in the afterburning chamber is maintained in the range from $1100{ }^{\circ} \mathrm{C}$ to $1200{ }^{\circ} \mathrm{C}$. A highly efficient flue gas cleaning system is used to comply with environmental standards. The advantage of the use of rotary kilns is a stable incineration, complete burning of organic debris and continuous slag removal. Rotary kiln combustion plants are more versatile in the sense that they are applicable to the destruction of solid waste, sludge and container waste, as well as liquids. The rotary kiln is a horizontal cylindrical refractory shell mounted on a small slope. The rotation of the housing ensures the transport of waste through the furnace, as well as improved mixing of burning solid waste. Wastes in the furnace can be moved in two ways: countercurrent or concurrent to gas flow. The heat energy is released after the incineration of waste. The realization of the heat received from combustion in a conventional way is difficult, since the plant is remote from heat consumers, and the generation of electricity requires capital investments. A variant of heat realization for the technology of obtaining building materials is proposed. The technologies described above (burning of phosphogypsum and incineration of waste) can be realized separately. However, together they make it possible to obtain a synergistic effect in the form of a technology for the utilization of phosphogypsum, the production of a finished product using it from a renewable energy source - solid waste. Both technologies are remote from residential development.

\section{Basic Principles of Heat Treatment of Phosphogypsum}

Thermal treatment of phosphogypsum includes the following stages of the process: the supply of heat to the surface of particles or pieces of starting material, volatilization of physical moisture, heating of the material to the dehydration temperature and the chemical reaction of dehydration of phosphogypsum. Analysis of scientific research [9] on the utilization of phosphogypsum for the production of building gypsum and other building materials and products analysis revealed the problem of energy intensity of these technologies [10].

To the initial phosphogypsum it is necessary to transmit heat and transfer it to the particles of the material in order to start the process of dehydration of phosphogypsum. Such a process underlies the technology of obtaining all gypsum binders. The physical moisture begins to evaporate even with insignificant heating from $60-70^{\circ} \mathrm{C}$, simultaneously the crystallization water begins to split off from the molecules. The process proceeds very slowly at these temperatures. Intensive dehydration begins at material temperatures $97-105^{\circ} \mathrm{C}$. In standard factory technology, a temperature of $120-170^{\circ} \mathrm{C}$ is maintained to produce the hemihydrate. A further increase in temperature to $210^{\circ} \mathrm{C}$ leads to the appearance of dehydrated hemihydrates.

\subsection{Experiment on Roasting of Phosofogypsum}

For experimental studies was used waste from phosphorite raw materials - phosphogypsum from the dumps of the Dneprovsky Mineral Fertilizers Plant (Kamenskoe). Phosphogypsum is a finegraded powder is shown in figure 1, partially crumpled, easily gaining moisture.

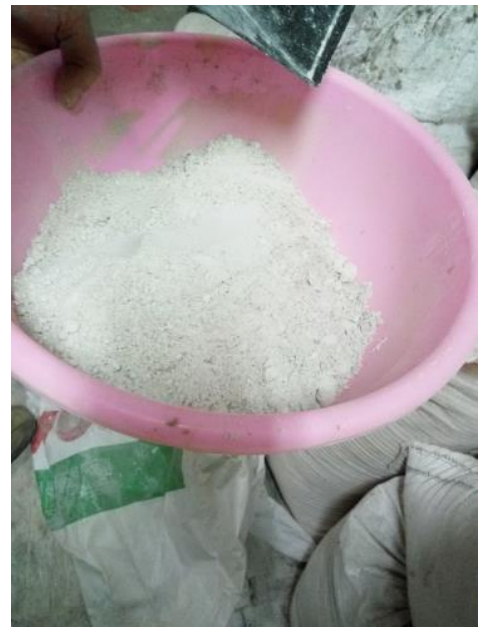

Fig. 1: Appearance of phosphogypsum

Before carrying out experimental studies X-ray structural analysis of phosphogypsum of apatite performed. Firstly, phosphogypsum was taken from dumps. Secondly, phosphogypsum was taken directly from the production line for the production of phosphoric acid. The main phase in the sample of fresh phosphogypsum is hemihydrates gypsum, with the presence of some amount of dihydrate gypsum. The fraction of the material was in the range $0.16 \div$ $0.315 \mathrm{~mm}$. Such a material fraction was chosen for all subsequent experiments. Experimental studies o identify the most rational parameters of the dehydrator, namely its operating temperature has been conducted. The temperature of a heat carrier (air) in the experiment varied from $175{ }^{\circ} \mathrm{C}$ to $350{ }^{\circ} \mathrm{C}$. The velocity of the heat carrier in the working zone of the dehydrator was $6.8 \mathrm{~m} / \mathrm{s}$. Depending on the temperature change, the material properties change, and hence the samples themselves. The influence of the time of heat treatment on the compressive strength of phosphogypsum samples is represented in the table 1 and in the figure 2 . The strength of samples from phosphogypsum binder was determined with a hardening time of 2 hours and 7 days.

Table 1: Effect of heat treatment on the compressive strength samples of gypsum

\begin{tabular}{|c|c|c|c|c|c|c|c|}
\hline \multirow{2}{*}{ Index } & \multicolumn{7}{|c|}{ Temperature of the transfer medium ${ }^{\circ} \mathrm{C}$} \\
\cline { 2 - 8 } & 175 & 200 & 225 & 250 & 275 & 300 & 325 \\
\hline $\begin{array}{c}\text { The com- } \\
\text { pressive } \\
\text { strength, } \\
\text { MPa (term } \\
\text { of hardening } \\
\text { 2 hours) }\end{array}$ & 0.5 & 4.0 & 4.9 & 5.5 & 5.4 & 4.5 & 2.5 \\
\hline $\begin{array}{c}\text { The com- } \\
\text { pressive } \\
\text { strength, } \\
\text { MPa (term } \\
\text { of hardening } \\
7 \text { days) }\end{array}$ & 3.0 & 11.7 & 14.3 & 16.0 & 16.6 & 16.0 & 14 \\
\hline
\end{tabular}




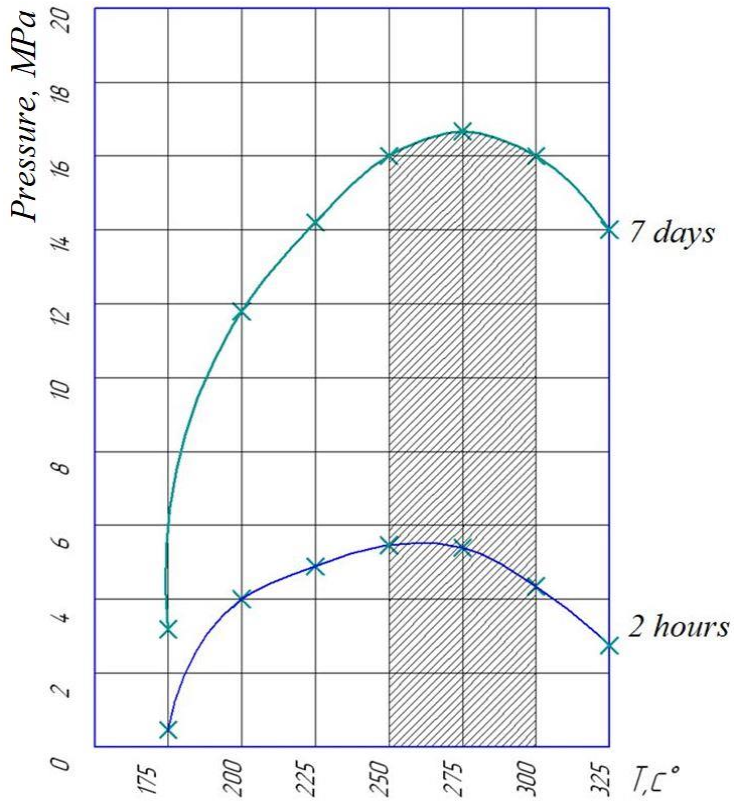

Fig. 2: The compressive strength of samples of gypsum.

As can be seen from Fig. 2, the compressive strength samples of gypsum increases from $2 \mathrm{MPa}$ at $2.0 \mathrm{~s}$ to $5 \mathrm{MPa}$ at $3.0 \mathrm{~s}$. This can be explained by the fact that as the time of heat treatment increases, the process of dehydration of gypsum passes fuller, which improves the strength of the samples.

The effect of coolant temperature on the strength of gypsum samples is represented in the table 2 and in the figure 3.

Table 2: Bending strength specimens

\begin{tabular}{|c|c|c|c|c|c|c|c|}
\hline \multirow{2}{*}{ Index } & \multicolumn{7}{|c|}{ Temperature of the transfer medium ${ }^{\circ} \mathrm{C}$} \\
\cline { 2 - 8 } & 175 & 200 & 225 & 250 & 275 & 300 & 325 \\
\hline $\begin{array}{c}\text { The bending } \\
\text { strength, MPa } \\
\text { (term of hard- } \\
\text { ening 2 hours) }\end{array}$ & 0.4 & 1.1 & 1.4 & 1.6 & 1.6 & 1.4 & 1.1 \\
\hline $\begin{array}{c}\text { The bending } \\
\text { strength, MPa } \\
\text { (term of hard- } \\
\text { ening 7 days) }\end{array}$ & 0.6 & 1.4 & 1.8 & 2.2 & 2.3 & 2.1 & 1.8 \\
\hline
\end{tabular}

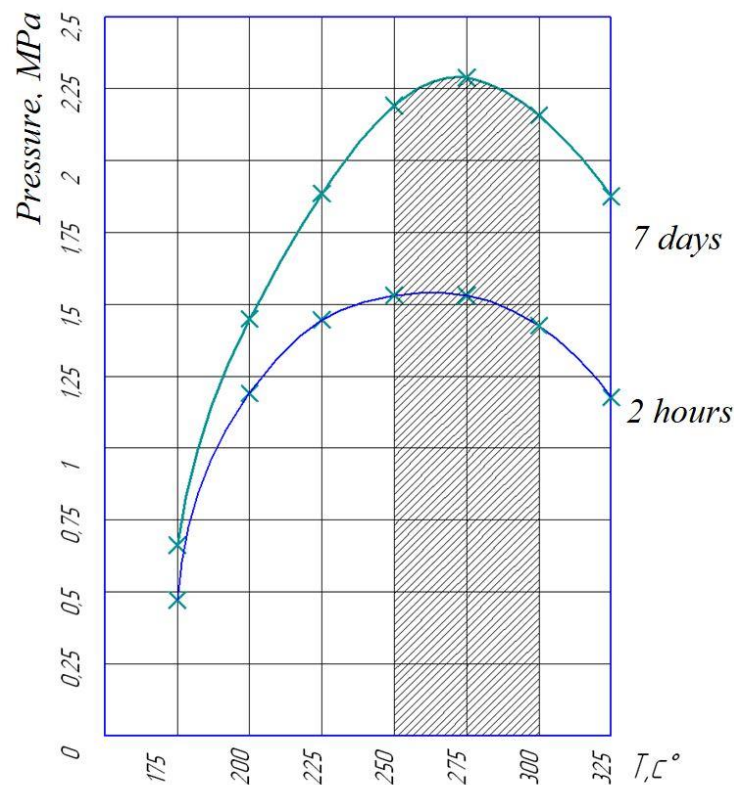

Fig. 3: Bending strength specimens.
The time for setting specimens of the gypsum binder was also determined, the results are in Figure 4.

Table 3: Effect of heat treatment time on the time of setting samples of gypsum

\begin{tabular}{|c|c|c|c|c|c|c|c|}
\hline \multirow{2}{*}{ Index } & \multicolumn{7}{|c|}{ Temperature of the transfer medium ${ }^{\circ} \mathrm{C}$} \\
\cline { 2 - 8 } & 175 & 200 & 225 & 250 & 275 & 300 & 325 \\
\hline $\begin{array}{c}\text { Time frame, } \\
\text { minutes (start) }\end{array}$ & 7.0 & 10.0 & 6.0 & 4.0 & 2.8 & 1.8 & 1.0 \\
\hline $\begin{array}{c}\text { Time frame, } \\
\text { minutes (fin- } \\
\text { ish) }\end{array}$ & 17.0 & 15.0 & 9.5 & 6.0 & 4.0 & 3.5 & 3.1 \\
\hline
\end{tabular}

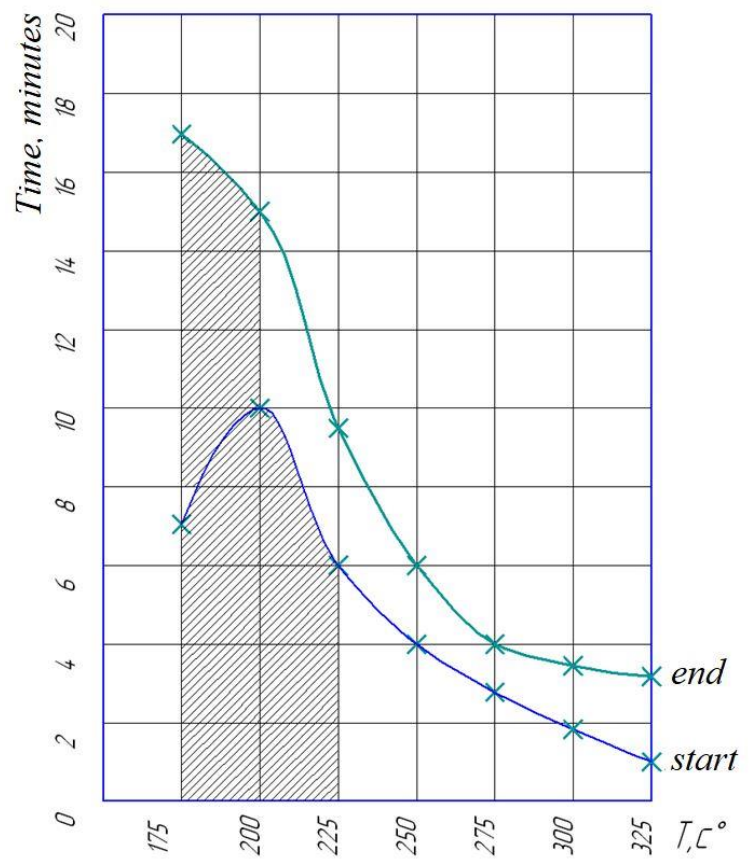

Fig. 4: Time of hardening specimens.

After heat treatment, phosphogypsum practically does not absorb moisture from the air. Therefore, to obtain a high-quality building material from phosphogypsum, roasting at a temperature of 250$300^{\circ} \mathrm{C}$ is require.

\section{Use of Waste Incineration Energy}

\subsection{Incineration of Waste}

The technology of incineration of solid waste with the use of a rotary furnace. Such a furnace design allows burning waste of various categories without prior preparation. The installation can be mobile and move to the storage location of the phosphogypsum dumps. A model of the completeness of combustion of solid waste in a rotary kiln was developed [11] and implemented a simulation system for the motion of gas flows based on finite element methods.

The model describes the temperature processes on the surface of the material (waste), regardless of the morphological composition of the waste, and therefore the heat of combustion (since this index is extremely unstable). Whatever the heating value of solid waste, the furnace maintains a certain temperature, at least $850^{\circ} \mathrm{C}$, burning additional fuel (gas or diesel), and the temperature in the afterburner should be within $1200^{\circ} \mathrm{C}$. The main direction for research is to obtain a temperature field on the surface of the waste and to maximize the use of the torch of additional fuel burners for completeness of waste incineration. Counter movement of solid waste and gases allows to use more coarse furnaces. This allows you to use mobile waste processing plants, reduce the consumption of additional fuel. 


\subsection{Roasting of Phosphogypsum by Use Heat from the Incineration of Waste}

The principle of the installation is as follows. Crushed phosphogypsum 1 (fig.5) through a hopper with a feeder and a conveyor system is fed to the roller crusher 2. After that, phosphogypsum is directed by a conveyor 3 in a drum-dryer 4 . The dried phosphogypsum is sent to the elevator 5 , then - conveyor for dry phosphogypsum 7. Wet gases 6 are released into the atmosphere. Dry phosphogypsum 8 is fed to a mill-dryer 9 . In the proposed version, a bowl-roll mill-dryer is used, developed at the Department of Mechanization of Construction Processes of Kharkiv National University of Civil Engineering and Architecture. Directly above the mill is a through separator. The mill-dryer 9 is equipped with an external combustion chamber 10 .

The fine particles of the material, passing the separator, flow upward into the shaft of the dryer 11, where effective heat exchange takes place in the suspended state. Shaft 11 is also used for further particle fractionation. From the shaft 11, the flow of the gas with small particles enters the centrifugal cyclone 12, in which the particles are separated from the gas that has received physical moisture from the material. The wet heat carrier through the flue gas line 13, the dust removal system and the smoke exhauster (not shown in the diagram) is discharged into the atmosphere. The dried material, precipitated, is collected in a bunker with a shutter at the bottom. By means of a screw feeder 15, material is fed into the lower part of the gas flue of pre-heating of the dry phosphogypsum 16. The material is picked up by a stream of hot gases that exit the cyclone 22 and is carried upward into the cyclone 17 At this time the material is heated and dried. In the cyclone 17, the particles are separated from the wet gases. Gases are discharged through the pipe 18 into the atmosphere, and the hot and absolutely dry particles of phosphogypsum from the cyclone 17 are drained into the dehydrator 20 . Here is the transformation of phosphogypsum into hemi water gypsum in a suspended condition in the flow of hot gas. Water is released from phosphogypsum.

During the dehydration reaction, the water molecules are broken with the ions $\mathrm{Ca}^{2+}$ and $\mathrm{SO}_{4}{ }^{2-}$ and the water is removed from the crystal lattice in the form of superheated steam. As a result, $\beta$ modification of calcium sulfate hemihydrate is formed. The chemical reaction of this process (dehydration):

$$
\mathrm{CaSO}_{4} \cdot 2 \mathrm{H}_{2} \mathrm{O} \rightarrow \mathrm{B}-\mathrm{CaSO}_{4} \cdot 0.5 \mathrm{H}_{2} \mathrm{O}+1.5 \mathrm{H}_{2} \mathrm{O} \uparrow .
$$

In cyclone 22, the flow is separated: particles of hemi water gypsum down and collected in hopper 23. Wet hot gases escape upward from cyclone 22 to tube 16 . The main amount of heat that is used in technology is realized in dehydrator 20 (Fig.5). According to the proposed scheme, this heat is supplied from a municipal waste incinerator (21 in Fig.5).

The waste is incinerated in a rotary kiln 25 , which is loaded with waste by a feeder 26 . A rotary kiln reaches a temperature of 850 $1000^{\circ} \mathrm{C}$. In the furnace, in addition to the waste, additional fuel can be burned, if necessary. Additional fuel is also used when the rotary kiln is tapped to start. When starting, the furnace is heated to a temperature of $400^{\circ} \mathrm{C}$, and then the supply of waste begins. As fuel, diesel fuel or gas can be used. Fuel is burned in a coaxial burner. The direction of movement of the waste 27 and the direction of movement of the gases 28 in the furnace are counterpropagating. According to the authors, the oncoming traffic has ad- vantages in comparison with the associated movement of waste and gas.

Temperatures of $850-1000^{\circ} \mathrm{C}$ are not sufficient to neutralize harmful gaseous components. Therefore, the gases from the rotary kiln 25 are discharged into the afterburning chamber 29 . This chamber is equipped with burners 30 . Here, at a temperature of 1000$1200^{\circ} \mathrm{C}$, in the conditions of excess oxygen, the major part of the organic constituents decompose.

The flue gases after the afterburner chamber 29, after passing the gas conduit 31, enter the heat recuperator 32 , where heat for domestic needs is taken away and the gases are cooled to $500-600^{\circ} \mathrm{C}$. After that, the flue gases through the gas conduit enter the dust collector 33, in which it is cleaned from dust of high density. After the dust collector, the partially purified gases enter the catalytic reactor 34 . In the reactor at a temperature of $500-600^{\circ} \mathrm{C}$, the residues of the organic constituents are oxidized and the nitrogen oxides are reduced to molecular nitrogen. A gas stream with such a temperature is best suited for heat treatment of phosphogypsum in a suspended state. Gases are sent to dehydrator 20. Here, the heat of the gases is transferred to the finely ground particles of phosphogypsum. The gases lower their temperature to (120$140)^{0} \mathrm{C}$, and the material temperature rises to the decomposition temperature of calcium sulfate dihydrate $(105-120)^{0} \mathrm{C}$.

With this use of gases, there is no need for a heat recovery unit, since heat is consumed for heat treatment of phosphogypsum. The plant for roasting phosphogypsum is itself a heat recovery unit. In this case, the heat will be utilized more qualitatively, and therefore the temperature of the gases at the outlet from the unit will be (70$90)^{\circ} \mathrm{C}$. Better utilization of heat is attributed to heat transfer by direct contact of fine-grained material particles with a gas stream. It is known that the heat transfer from gases to the material through the wall is less effective than heat transfer to small particles with direct contact during the movement of the gas stream.

A heat generator can be installed in front of the dehydrator 20 (heat generator not shown in the scheme (Fig. 6)). It will only be used if the incinerator is not working.

Solid slags 35 are transported to the landfill and can be used for the production of building materials or for the construction of roads.

\section{Results}

To obtain a high-quality building material from phosphogypsum, a roasting temperature in the range of $250-300^{\circ} \mathrm{C}$ is required. Samples of material treated at a temperature of $250^{\circ} \mathrm{C}$ and $275^{\circ} \mathrm{C}$ had the highest compressive strength and bending strength. The sufficient time for setting of the gypsum binder is ensured at a temperature of $275^{\circ} \mathrm{C}$. Flue gases from incineration of waste provide such a temperature. Flue gases pass through the afterburner chamber, enter the heat recuperator and give off heat for internal needs. The temperature of the gases after the recuperator is $500^{\circ} \mathrm{C}$. The gases are directly in contact with the material to which the heat is transferred. The contact surface is large, since the material is finely dispersed and the particles of the material are small. The fine particles receive heat in a few seconds. The development of a complex that processes wet and highly adhesive phosphogypsum using the heat of combustion of alternative fuel (municipal waste) is consistent with the synergetic concept of environmentally efficient utilization. 




Fig. 5: Complex of roasting of phosphogypsum with the use of heat from incineration of waste (counter movement of solid waste and gases).

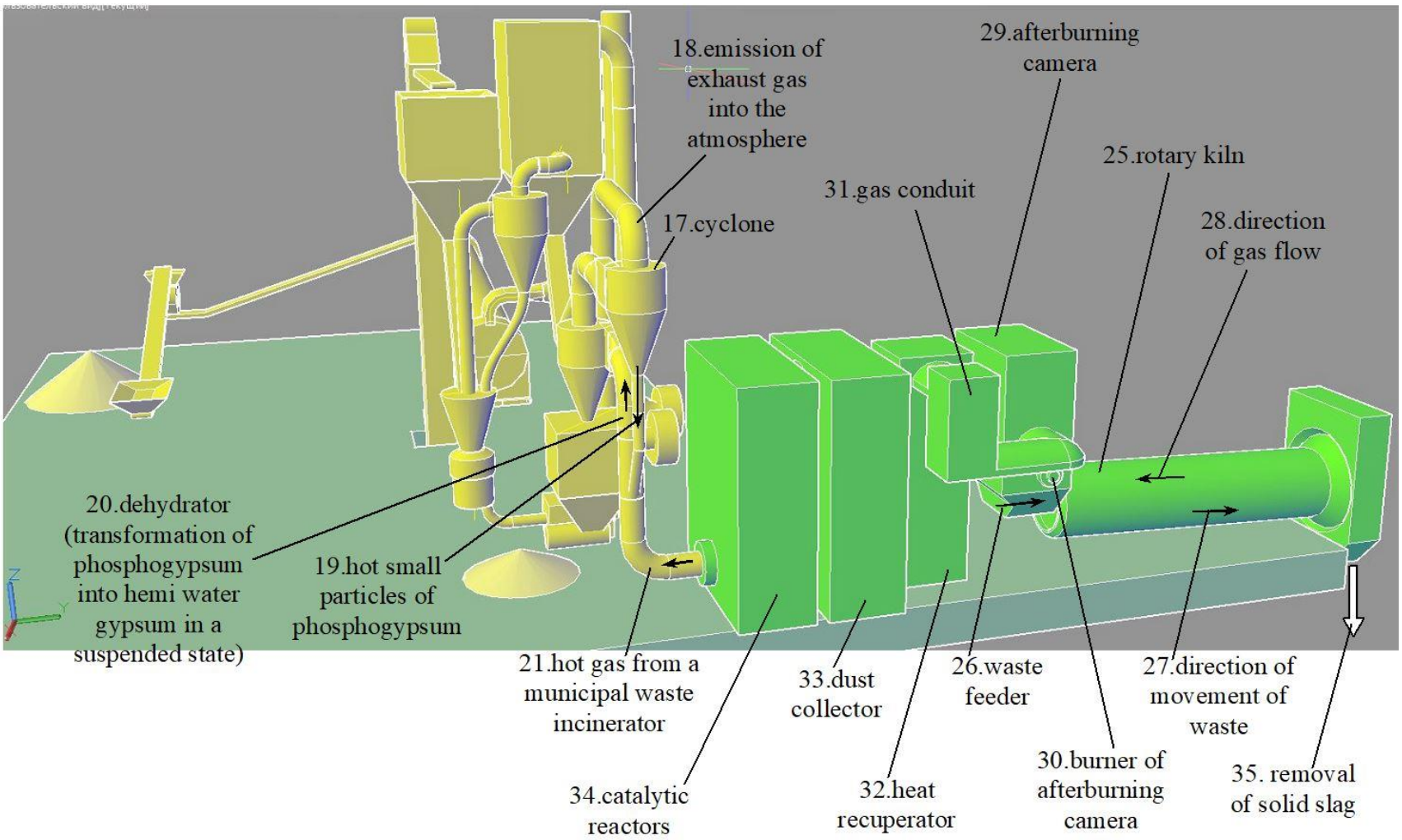

Fig. 6: Complex of roasting of phosphogypsum with the use of heat from incineration of waste (counter movement of solid waste and gases) in profile 


\section{Conclusion}

A solution to reduce the number of phosphogypsum dumps and solid waste landfills has been proposed. The developed installation maximizes the energy of waste incineration. The dehydrator, which is a mine, is also an indicator of energy-efficient production of the finished product. The proposed technology is an important and urgent task both from the energetic and environmental viewpoint. The development of a more efficient method for utilizing the heat of flue gases from incineration furnaces will permit a more rational use of the heat energy released by incineration of waste. Such an installation has several important advantages, namely: the processes of heat and mass transfer are significantly intensified, which is associated with an increase in the contact surface of phases and an increase in the coefficients of heat and mass transfer; continuous input and output of the solid phase; simplicity and compactness of the structure; the possibility of automation of the process.

\section{References}

[1] Tayibi H., Choura M., López F.A., Alguacil F.J. and LópezDelgado A., "Environmental impact and management of phosphogypsum", Journal of Environmental Management, Vol. 90, (2009), pp. 2377-2386, https://doi.org/ 10.1016/j.jenvman.2009.03.007.

[2] Santos A.J.G., Mazzilli B.P, Fávaro D.I.T., Silva P.S.C. "Partitioning of radionuclides and trace elements in phosphogypsum and its source materials based on sequential extraction methods", Journal of environmental radioactivity, Vol.87, Is.1, (2006), pp.52-61, https://doi.org/10.1016/j.jenvrad.2005.10.008.

[3] Gorakh S. Bandgar, Madhav B. Kumthekar, Amarsinh B. Landage, "A Review of Effective Utilization of Waste Phosphogypsum as a Building Material", International Journal of Engineering Research, Vol.5, Is.1, (2016), pp:277-280, http://dx.doi.org/10.17950/ijer/v5is1/065 .

[4] Mohammad A. Aliedeh and Nabeel A. Jarrah, "Application of full factorial design to optimize phosphogypsum beneficiation process (P2O5 Reduction) by using sulfuric and nitric acid solutions", Sixth Jordanian International Chemical Engineering Conference, Amman, Jordan, (2012), pp:1-10, available online: http://www.jeaconf.org//.

[5] Paige-Green, P., Gerber, S. "An Evaluation of the Use of Byproduct Phosphogypsum as a Pavement Material for Roads", South African Transport Conference "Action In Transport for the New Millenium", (2000), Conference papers.

[6] Stanisław Folek, Barbara Walawska, Bożena Wilczek and Jolanta Miśkiewicz, "Use of phosphogypsum in road construction", Polish Journal of Chemical Technology, Vol.13, Is.2, (2011), pp:18-22, https://doi.org/10.2478/v10026-011-0018-5.

[7] C. Papastefanou, S. Stoulos, A. Ioannidou, M. Manolopoulou, "The application of phosphogypsum in agriculture and the radiological impact", Journal of Environmental Radioactivity, Vol.89, Is.2, (2006), pp:188-198, https://doi.org/10.1016/j.jenvrad.2006.05.005.

[8] Niessen W.R., Combustion and incineration processes, New York Basel Dekker, (2002), pp: 1-715p.

[9] Tayibi H, Choura M, López F.A, Alguacil FJ, López-Delgado A., "Environmental impact and management of phosphogypsum (Review)", Journal of environmental management, Vol.90, No.8, (2009), pp.2377-86. https://doi.org/10.1016/j.jenvman.2009.03.007. 2009.

[10] Jiakuan Yang, Wanchao Liu, Lili Zhang, Bo Xiao, "Preparation of load-bearing building materials from autoclaved phosphogypsu", Construction and Building Materials, Vol.23, No.2, (2009), pp.687693. doi.org/10.1016/j.conbuildmat.2008.02.011.

[11] Krot, O.P. "Modeling of installations with a rotary kiln for thermal decontamination of wastes", Problemele energeticii regionale, Vol.1, No.36, (2018), pp:44-57. http://dx.doi.org/ 10.5281/zenodo. 1217255 . 